\title{
Song-type switching rate in the chaffinch carries a message during simulated intrusion
}

\author{
Krzysztof Deoniziak $^{1,2}$ (D) Tomasz S. Osiejuk ${ }^{1}$ (i)
}

Received: 21 September 2019 / Revised: 26 February 2020 / Accepted: 4 March 2020 / Published online: 30 March 2020

(C) The Author(s) 2020

\begin{abstract}
Birds communicate their motivation and willingness to escalate a territorial conflict with a variety of agonistic signals. One of these, song-type switching, has been suggested to be a conventional signal in male-male interactions. However, this behavior does not show a consistent pattern across species. In this study, we asked whether variation in song-switching rate carries a message for song receivers among territorial chaffinches, Fringilla coelebs. Chaffinch song is well described, but only a few studies have focused on the communicative function of song-type switching or bout duration. Using data from playback experiments, we show here that variation in song-type switching rate affects the response of chaffinches. In response to the low switching rate treatment, territorial males began to sing later, produced fewer songs and more rain calls, decreased flight intensity, and spent more time close to the speaker than during playback of songs with a high switching rate. Our results provide strong evidence that the song-type switching rate is an agonistic signal in the chaffinch and that territorial males exhibit a stronger response toward rivals that sing with a lower song-type switching rate. A secondary purpose of our study was to determine the receivers' response with respect to their own song rate and song repertoire. We found that the reaction of tested males was correlated with their own spontaneous song rate. This implies that a male's response to stimuli may be predicted on the basis of his own song output.
\end{abstract}

\section{Significance statement}

Using playback experiments, we show that birds' responses to simulated territorial intrusion vary not only with the type of stimulus but also with the tested males' spontaneous song output. We found that, from the perspective of the song receiver, variation in switching rate carries a message for territorial chaffinches. Our findings add a new example of agonistic signaling in which territorial males exhibit a stronger response toward rivals singing with lower song-type switching rate, which up to now has only been demonstrated in a few species. Moreover, our results show that a male's response to playback could be predicted using his song output. This may be associated with motivation and willingness to escalate a conflict and could possibly also indicate a male's quality.

Keywords Animal communication $\cdot$ Birdsong $\cdot$ Aggressive signaling $\cdot$ Song-type switching $\cdot$ Song rate $\cdot$ Fringilla coelebs

Communicated by H. Brumm

Krzysztof Deoniziak

krzysztofdeo@gmail.com

Tomasz S. Osiejuk

osiejuk@amu.edu.pl

1 Department of Behavioural Ecology, Institute of Environmental Sciences, Faculty of Biology, Adam Mickiewicz University, Uniwersytetu Poznańskiego 6, 61-614 Poznań, Poland

2 Laboratory of Insect Evolutionary Biology and Ecology, Faculty of Biology, University of Bialystok, Konstantego Ciołkowskiego 1J, 15-245 Białystok, Poland

\section{Introduction}

Birdsong carries important information that is utilized both in mating and agonistic behavior (Catchpole and Slater 2008). In male-male competition, conflicts arise over limited resources such as mates or breeding territory (Bradbury and Vehrencamp 2011). Since engaging in physical fights is costly, males can communicate their motivation and willingness to escalate a territorial conflict with their vocal signals (Todt and Naguib 2000; ten Cate et al. 2002). Various aspects of birdsong have been found to be associated with different outcomes in territorial conflicts (Vehrencamp 2000; Searcy and 
Beecher 2009). In addition to repertoire size (Balsby et al. 2017; Byers 2017), song performance parameters such as frequency matching (Morton and Young 1986; Horn et al. 1992), soft song (Hof and Hazlett 2010; Jakubowska and Osiejuk 2018), vocal performance (Moseley et al. 2013; Phillips and Derryberry 2017), or song-type matching (Krebs et al. 1981; King and McGregor 2016) can play a role during aggressive interactions by birds.

Another aspect of birdsong that can serve as an agonistic signal in aggressive contexts is song-type switching (Vehrencamp 2000; Searcy and Beecher 2009), which is used by songbirds that possess a repertoire of different song types. In many repertoire species, individuals sing with eventual variety, i.e., they repeat a given song type several times, forming a song type bout, and then switch to another song type from their repertoire (Catchpole and Slater 2008). Many hypotheses have been put forward to explain why birds switch between song types. Hartshorne (1956) argued that it serves to prevent monotony and reduce the habituation of the receiver. However, this idea has proven to be controversial, and further studies provided little support for it (i.e., Dobson and Lemon 1975; Weary and Lemon 1988; Hughes 2008). Song-type switching was also suggested to be a strategy for preventing muscle fatigue, thus allowing males to sustain a high production rate (Lambrechts and Dhondt 1988). To date, though, most studies testing predictions of this hypothesis cast doubt on it (e.g., Weary et al. 1988; Weary et al. 1991; Brumm et al. 2009). Similarly, the Beau Geste hypothesis argues that by switching between song types, males try to deceive conspecifics about territory occupancy (Krebs 1977), but empirical support for this hypothesis is mixed (e.g., Krebs 1976; Slater 1978; Yasukawa and Searcy 1985; Haftorn 1995). Other proposed hypotheses suggest that song-type switching is an outcome of sexual selection for repertoire size and that switching between song types during vocal interactions carries a message to the receiver (Catchpole and Slater 2008; Brumm et al. 2009).

Males often switch between song types in aggressive interactions (Searcy and Beecher 2009) and this was suggested to be a conventional signal of aggressive intentions or motivation (Vehrencamp 2000). However, the available data do not show a consistent pattern across the species that have been studied thus far. Increased switching was documented in aggressive contexts and was connected with a stronger response in such species as the song sparrow (Melospiza melodia; Kramer and Lemon 1983; Kramer et al. 1985; Searcy et al. 2000), western meadowlark (Sturnella neglecta; Horn and Falls 1991), tropical mockingbird (Mimus gilvus; Botero and Vehrencamp 2007), and Carolina wren (Thryothorus ludovicianus; Simpson 1985). However, this result was not corroborated by studies of red-winged blackbirds (Agelaius phoeniceus; Searcy and Yasukawa 1990), dunnocks, (Prunella modularis; Langmore 1997), and banded wrens (Thryophilus pleurostictus; Molles and Vehrencamp 1999; Molles 2006), in which song-type switching rates actually decreased during male-male interactions. Furthermore, plain wrens (Thryothorus modestus) exhibited no differences in switching rates, as well as in song production rates or approach behavior, in response to switching and non-switching playback stimuli (Marshall-Ball and Slater 2004). Switching rate also failed to predict whether birds would attack a simulated intruder in black-throated blue warblers (Dendroica caerulescens; Hof and Hazlett 2010), swamp sparrows (Melospiza georgiana; Ballentine et al. 2008), and song sparrows (Searcy et al. 2006).

In this study, we investigate the role of switching rate from the receiver's perspective in the chaffinch, Fringilla coelebs. Chaffinch song has been studied intensively, but few studies have focused on the communicative function of song-type switching or bout duration. Variation in song-type switching rate occurs throughout the population (i.e., Slater 1981; Riebel and Slater 1999a; Deoniziak and Osiejuk 2016), but no evidence has been found that it is copied from tutors (Riebel and Slater 1999b). A study by Riebel and Slater (1999a) found that song bout duration is controlled by a temporal limit which may be modified by a male's motivational state. Moreover, males decrease song-type switching rate when they match the song type of a simulated rival (Riebel and Slater 2000), as found in cardinals (Cardinalis cardinalis; Lemon 1968) and song sparrows (Nielsen and Vehrencamp 1995). These elongated bouts of matched-type countersigning may allow opponents to exchange additional information about each other (Nielsen and Vehrencamp 1995). Of the three criteria proposed by Searcy and Beecher (2009) to determine if a given singing behavior is aggressive, there is some evidence that a decrease in switching rate may fulfill the "context criterion," meaning that a signal characterized by a lower switching rate is agonistic. However, we still lack data from the chaffinch to establish whether a lower switching rate predicts aggressive escalation by the signaler (predictive criterion) or results in a different response from a receiver when compared with a high switching rate (response criterion).

Chaffinches were also found to use lower switching rates and thus to sing longer bouts of the same song type in the vicinity of noisy mountain streams than in quieter territories (Brumm and Slater 2006). Such changes in signal structure not only may be a result of long-term, ongoing selective pressure in acoustically demanding natural environments but may also represent developmental plasticity or phenotypic flexibility (Swaddle et al. 2015). A more recent study did not observe chaffinches using a similar strategy while singing in noisy urban environments, but this might have been caused by the relatively low noise levels observed at the urban site (Deoniziak and Osiejuk 2016). Instead, the authors found that the duration of a bout sequence was dependent on a male's song production rate and song repertoire, which are both important cues in mate choice and male-male competition (e.g., Radesäter et al. 1987; Alatalo et al. 1990; Hofstad et al. 2002; 
Hesler et al. 2012; Grunst and Grunst 2014; Phillips and Derryberry 2017; Szymkowiak and Kuczyński 2017; Opaev et al. 2019). Individuals that sang shorter song bouts possessed a larger repertoire size and delivered song at a higher rate, which could be a reflection of male quality. This relationship between song characteristics was not tested in the original work of Brumm and Slater (2006) but was observed to be not significant in a later complementary study (Brumm et al. 2009).

The present study aimed to address the following two questions: (1) Do song-type switching rates carry a message in malemale interactions in the chaffinch? (2) Do differences in song production rate and repertoire size among males lead to differences in their responses to territorial intrusion? To answer these questions, we conducted a playback experiment on a local population of chaffinches that inhabit forest patches in an urbanized landscape. During the experiment, we simulated territorial intrusion using playback characterized by either a short (high switching rate) or long (low switching rate) song bout sequence duration. We hypothesized that territorial chaffinches would show variation in their responses to song-type switching rate, as observed in previous studies on eventual-variety singers (e.g., Kramer et al. 1985; Simpson 1985; Horn and Falls 1991). Based on previous playback experiments on chaffinches, we predicted that stronger responses would involve an increase in the number of flights, time spent near the speaker, and calling frequency, as well as a decrease in song production (Pickstock and Krebs 1980; Slater 1981; Slater and Catchpole 1990; Leitão and Riebel 2003; Brumm and Ritschard 2011; Budka et al. 2019). Moreover, since song production rate and repertoire size may reflect a chaffinch male's quality (Deoniziak and Osiejuk 2016), we expected to find a relationship between these song characteristics and a male's response to territorial intrusion.

\section{Methods}

\section{Studied species and song characteristics}

The chaffinch is one of the most abundant European songbirds and a common urban dweller. It is a socially monogamous species in which males use their song mainly for female attraction and territorial defense (Riebel and Slater 1998; Leitão and Riebel 2003). Chaffinches are "eventualvariety" singers (Catchpole and Slater 2008). Their song can be divided into two parts: a trill (usually composed of two or three trill phrases, which consist of several repetitions of a particular syllable type) and a flourish (made up of a few syllable types that are generally not repeated). The combination of trill phrases with a flourish enables the classification of song types (Fig. 1). Males can possess up to six different song types in their repertoire, but typically only use two or three (Slater 1983).

\section{Site and timing}

The study was conducted in parks and forests within the city of Białystok, Podlaskie Voivodeship, Poland (N 53.129186, E 23.165154). Playback experiments were performed in forest patches of temperate and mixed coniferous forest dominated by the Scots pine, Pinus silvestris, and surrounded by major roads and high-density urban development. Trials were conducted between 22 April and 6 May in 2016 and 23 April and 6 May in 2017, during morning hours (6:30 am-10:30 am).

\section{Playback preparation}

All songs used in the experiment were recorded during breeding seasons between 2012 and 2015 in western Poland (N 52.716508 , E 16.739842), about $450 \mathrm{~km}$ away from the playback site. In this way, we ensured that playback stimuli were perceived as a stranger male by each male being tested, since previous studies have shown that the chaffinch response is weaker toward familiar songs (Pickstock and Krebs 1980; Slater 1981). Males were recorded in $48-\mathrm{kHz}$ sampling frequency and 16-bit resolution with a Marantz PMD670 recorder (Marantz Professional, Kanagawa, Japan) coupled with a Sennheiser ME67 shotgun microphone (Sennheiser, Wedemark, Germany). We selected 36 songs with high signal-to-noise ratios, each one from a different male. We then classified their song types using the methods of previous studies on chaffinches (Slater and Ince 1979; Slater et al. 1980). All recorded songs were filtered (high-pass, $1.0 \mathrm{kHz}$; low-pass $10.0 \mathrm{kHz}$ ) before the preparation of playback stimuli.

Each playback stimulus was created from two randomly selected songs recorded from two different males; all pairs were unique in order to avoid pseudoreplication. Each playback stimulus had a duration of about 3 min and consisted of 18 songs that were repeated at a rate of six songs per minute, with 7-s intervals of silence between them, as undisturbed chaffinches have been shown to sing with a mean rate of about six songs per minute (Riebel and Slater 1999a, 2000), with the mean duration of intervals between songs reaching about $7 \mathrm{~s}$ (Deoniziak and Osiejuk 2016). In the short-bout treatment, each song of a given song type was repeated three times before switching to the next type, which corresponded with a short bout within the natural range of bout duration (Riebel and Slater 1999a; Deoniziak and Osiejuk 2016). This formed a playback stimulus that contained six song bouts with five switches between song types. In the long-bout treatment, songs were repeated nine times in a song bout to form playback stimuli containing two bouts and one switch between song types. This corresponded with a long bout within the natural range of bout duration (Riebel and Slater 1999a; Deoniziak and Osiejuk 2016). The volume of each playback was set to $85 \pm 1 \mathrm{~dB}$ SPL at 1-m distance from the speaker (Leitão and Riebel 2003), measured with a CHY 650 digital 
Fig. 1 Examples of two chaffinch songs belonging to different song types

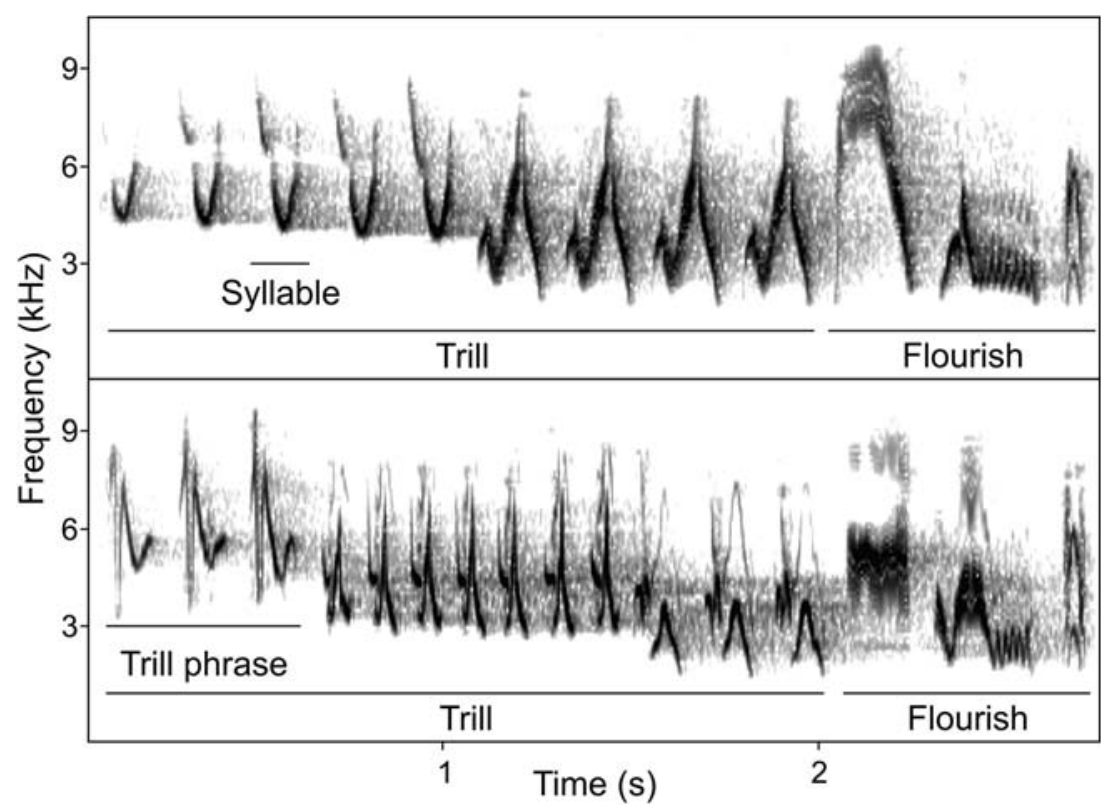

sound level meter (CHY Firemate Co., Ningbo, China; range, 35-130 dB SPL re $20 \mu \mathrm{Pa}$; time weighting, fast; frequency weighting, A); natural chaffinch song amplitudes range between 78 and $87 \mathrm{~dB}$, with a mean of $82 \mathrm{~dB}$ (Brumm and Ritschard 2011). Digital editing, construction, and analysis of the playback files was conducted with Raven Pro 1.5 Beta Version Build 23 (Cornell Lab of Ornithology, Ithaca, USA). Sound files were visualized with the following spectrogram parameters: window type, Hann; FFT length, 512; temporal overlap, 50\%; time resolution, $5.8 \mathrm{~ms}$; frequency resolution, 86.1 Hz.

\section{Playback procedure}

After finding a singing male, we recorded his activity for $15 \mathrm{~min}$ and simultaneously monitored the territorial behavior of neighboring chaffinch males. During this time, we mapped the outermost song posts of the tested male, which were used to define the middle of his territory (Saur et al. 1996). We proceeded with the experiment only when there were no other chaffinches singing within $100 \mathrm{~m}$ of the outermost song posts of the subject male. To set up the experiment, a black UE Boom speaker (Logitech, Lausanne, Switzerland) was placed on a black tripod (1.5 $\mathrm{m}$ above the ground) in the middle of the territory. We then marked distances of $5 \mathrm{~m}$ from the speaker in all four cardinal directions with bamboo sticks. When the playback arena was prepared, we moved back to a distance of $10 \mathrm{~m}$ from the speaker, allowing us to have a clear view of the surroundings. No approach to the speaker by the territory owner was observed prior to the start of playback.

Altogether, we tested 30 territorial chaffinch males. Half of the males received the short-bout treatment, with the remaining half being exposed to the long-bout treatment. We only began the experimental procedure when the tested male was singing. Each experiment consisted of three 3-min phases. During the phase prior to playback (PRE), we recorded the unmodified behavior of the territorial male. After $3 \mathrm{~min}$, the playback phase began (EXP), which was followed by the observation phase (OBS). Playback files were assigned to tested males in an alternating order between long and short treatments. All vocal responses of the tested males were recorded using a Tascam DR680 MKII recorder (TEAC Corporation, Montebello, USA), coupled with a Sennheiser ME67 shotgun microphone (Sennheiser, Wedemark, Germany). Simultaneously, vocal commentary on the behavior of each tested male was recorded with a Sennheiser ME62 omnidirectional microphone (Sennheiser, Wedemark, Germany) connected to the second channel of the same recorder. Recordings were saved as a PCM WAV file with a 44.1-kHz sampling frequency and 16-bit resolution.

In order to control for the potential influence of the noisy urban environment on a male's response to the playback, the level of ambient noise present within each male's territory was characterized immediately after the end of the OBS phase. The main source of anthropogenic noise was traffic, since the territories of all tested males were located in parks and urban forests near major roads. Five measurements of ambient noise level were conducted in 5-s time intervals with a CHY 650 digital sound level meter (time weighting, fast; frequency weighting, A) and were later averaged for analysis. The noise levels observed in the tested males' territories ranged from 40.7 to $56.8 \mathrm{~dB}$ (median, $50.3 \mathrm{~dB}$ ). There were no significant differences in the noise levels in the territories of males treated with short-bout (mean $+\mathrm{SD}, 50.3 \pm 4.10 \mathrm{~dB}$ ) and long-bout (mean + SD: $49.4 \pm 4.76 \mathrm{~dB}$ ) stimuli (Mann-Whitney $U$ test, $\left.N_{\text {short }}=15, N_{\text {long }}=15, Z=-0.726, p>0.05\right)$. 
It was not possible to record data blindly given that the playback treatments were apparent to the observers. The tested males were not banded before the experiment to avoid subjecting them to an experience which has been observed in chaffinches to modify later responses (Budka et al. 2019). To prevent an individual male from being tested more than once, each experiment was conducted on a singing male that was at least $300 \mathrm{~m}$ away from other tested males within a single forest patch. Additionally, during song analysis, we searched for matching song repertoires among the tested males, which could indicate whether any birds were unintentionally resampled. We found no individuals with identical repertoires.

\section{Response variables}

To describe the behavioral response of the tested males, we chose response variables that have been analyzed in previous playback studies of chaffinches (Slater 1981; Slater and Catchpole 1990; Leitão and Riebel 2003; Brumm and Ritschard 2011; Budka et al. 2019). We recorded five characteristics of bird movement: latency of the first flight after playback start, number of flights during EXP phase, number of flights during OBS phase, time spent within $5 \mathrm{~m}$ of the speaker during EXP phase, and time spent within $5 \mathrm{~m}$ of the speaker during OBS phase. We also recorded the following vocal characteristics: latency of the first song sung after playback start, number of songs during PRE phase, number of switches between song types during PRE phase, number of songs during EXP phase, number of songs during OBS phase, number of rain calls during EXP phase, and number of rain calls during OBS phase.

The number of songs recorded during the 3-min PRE phase was used to measure the spontaneous song rate of the tested male (songs $/ \mathrm{min}$ ). Additionally, the repertoire size of each tested male was defined using 50 continuous songs recorded during the observation period prior to the EXP phase. This time frame was chosen because males usually present their whole repertoire within a sample of this size (Slater et al. 1980). Chaffinches have several call types they use for specific contexts. For this study, we only focused on one of these, the so-called rain calls (also referred to in the literature as "hrreet" calls; Marler 1956), rather than the "chink" call which is more widely used during playback experiments. The two calls seem to have different functions (Marler 1956), and a recent study showed different patterns of utilization during different phases of playback experiments (Budka et al. 2019). Rain calls are produced exclusively by males and only during the breeding period of the year. Saur et al. (1996) found that they are utilized almost exclusively inside a male's own territory and therefore seem to be connected with declaring territory ownership. An earlier study also suggested that they are a substitute for song (Detert and Bergmann 1984). An example of a rain call from one of the tested males is available through https://www.xeno-canto.org/490825.

\section{Statistical analysis}

We performed a principal component analysis (PCA) to reduce the responses measured to a smaller number of variables. Here, six of the original response variables were chosen on the basis of the Kaiser-Meyer-Olkin measure of sampling adequacy (Table 1). We decided to exclude variables that described calls during playback from the PCA based on the low estimation of communalities (0.273). Communalities represent the overall importance of variables in the PCA as a whole, and those with less than 0.5 can be considered to be too low, since they share less than half of their variability with the other variables (Larose and Larose 2015). We also excluded variables that described time spent within $5 \mathrm{~m}$ of the speaker during the EXP and OBS phases, since their presence in the PCA lowered the Kaiser-Meyer-Olkin measure of sampling adequacy to "miserable" levels (KMO below 0.6; Kaiser and Rice 1974).

We obtained two PCA components with eigenvalues higher than 1 , which together accounted for $72.5 \%$ of the overall variance. PC1 represented the vocal response of territorial males. It was negatively correlated with song production during the EXP and OBS phases and positively correlated with the latency of first song after playback start and the call response during the OBS phase. Therefore, higher PC1 values indicate that in response to playback tested males produced more rain calls, sang fewer songs, and began to sing later. PC2 described the movement response during the EXP and OBS phases and was positively correlated with the number of flights (Table 1).

Next, we used generalized linear models (GLM) to compare the responses described with the two PCA components

Table 1 Eigenvalues, cumulative variance explained, and weightings of the original variables in the two principal components extracted from the six original response variables

\begin{tabular}{lll}
\hline Kaiser-Meyer-Olkin measure of sampling adequacy & 0.693 & \\
Bartlett test of sphericity & 68.748 & \\
$d f$ & 15 & \\
$P$ & $<0.001$ & \\
Original response variable & PC1 & PC2 \\
& Vocal & Flight \\
Latency of first song after playback start & 0.837 & 0.212 \\
Songs during EXP phase & -0.727 & -0.222 \\
Songs during OBS phase & -0.875 & -0.008 \\
Calls during OBS phase & 0.839 & 0.178 \\
Flights during EXP phase & 0.305 & 0.810 \\
Flights during OBS phase & 0.038 & 0.880 \\
Eigenvalue & 2.793 & 1.555 \\
$\%$ of variance explained & 46.545 & 25.920 \\
\hline
\end{tabular}

Measures that contributed most to the particular compound variable are in italic 
between playback treatments. Predictor variables and covariates in the GLM were day of the season (22 April = 1), ambient noise level (dB SPL), treatment (short bout $=1$; long bout $=2$ ), song rate (number of songs sung per minute by tested males during PRE phase), repertoire size of the tested male, and the presence of other singing males in the background $(0=$ none, $1=$ one singing male, $2=$ two or more singing males). The timing of a trial, expressed as day of the season, accounted for possible changes in the strength of a response during the breeding season. Models included the entire set of variables and all of the possible combinations between them. Afterwards, we compared candidate models using values of Akaike's information criterion $\left(\mathrm{AIC}_{\mathrm{c}}\right)$ that were corrected for small sample sizes. Models were ranked using $\triangle \mathrm{AIC}_{\mathrm{C}}$, the difference between the best model (lowest $\mathrm{AIC}_{\mathrm{c}}$ value) and the model being compared. In all cases, the results from the described models fit the data better than the null model. We converted $\mathrm{AIC}_{\mathrm{c}}$ values for the best-fit models $\left(\Delta \mathrm{AIC}_{\mathrm{C}}<2\right.$; Richards 2005$)$ into two measures in order to assess the relative strength of models. Akaike weight $\left(w_{i}\right)$ provided normalized relative model likelihoods, with higher values indicating the model with the best predictor set. The evidence ratio (ER) enabled the direct comparison of models to the model with the best fit (Symonds and Moussalli 2011). The normality of variables was tested using a KolmogorovSmirnov one-sample test. All of the statistical analyses were two-tailed and were performed using IBM SPSS Statistics v. 24 (IBM Corp, Chicago, IL, USA). Figures were created with IBM SPSS Statistics v. 24 and CorelDRAW X5 (Corel Corporation, Ottawa, Canada).

\section{Results}

During the PRE phase, tested males sang an average of 6.7 songs per minute, with no significant difference between males treated with short- and long-bout stimuli (MannWhitney $U$ test, $N_{\text {short }}=15, N_{\text {long }}=15, Z=-0.522$, $p>0.05$ ). Similarly, males switched between song types during the PRE phase 2.5 times on average, with no significant difference between males from both treatments (MannWhitney $U$ test, $N_{\text {short }}=15, N_{\text {long }}=15, Z=-0.401, p>0.05$ ). The reaction of tested males to playback was immediate: they stopped singing and began to fly toward the speaker. We found no significant differences in the latency of first flight between treatments (Mann-Whitney $U$ test, $N_{\text {short }}=15$, $N_{\text {long }}=15, Z=-1.307, p>0.05$; Fig. 2 ) or in the latency of first song sung after playback start (Mann-Whitney $U$ test, $N_{\text {short }}=15, N_{\text {long }}=15, Z=-1.482, p>0.05 ;$ Fig. 2 ). The only significant difference observed among the original response variables regarded the number of flights during the OBS phase (Mann-Whitney $U$ test, $N_{\text {short }}=15, N_{\text {long }}=15, Z=-2.030$, $p=0.042$; Fig. 2).
The vocal response (PC1) of tested males differed significantly between treatments (Mann-Whitney $U$ test, $N_{\text {short }}=15$, $N_{\text {long }}=15, Z=-2.012, p=0.044 ;$ Fig. $3 \mathrm{a}$ ). The best-fit GLM revealed that playback treatment and spontaneous song rate explained a significant amount of variation in males' vocal responses (Table 2). In response to the short-bout treatment, tested males began to sing earlier, produced more songs, and made fewer rain calls than when they were exposed to the long-bout treatment (Table 2). Similarly, males with a higher song rate during the PRE phase resumed song production faster after playback start, sang more, and called less than males that sang fewer songs during the PRE phase (Fig. 4a).

The movement response (PC2) of tested males differed significantly between treatments (Mann-Whitney $U$ test, $N_{\text {short }}=15, N_{\text {long }}=15, Z=-3.215, p=0.001$; Fig. $3 b$ ). Similar to PC1, the strength of the movement response was best predicted by the stimulus type and the tested male's spontaneous song rate (Table 3). Territorial chaffinches reacted more intensely to the short-bout treatment by increasing their flight intensity during the EXP and OBS phases. Moreover, males that sang more intensively during the PRE phase responded to playback with fewer flights (Fig. 4b).

\section{Discussion}

We found that song-type switching rate evoked different responses from chaffinch males during simulated male-male interactions. In response to the low switching rate treatment, territorial males began to sing later, produced fewer songs and more rain calls, decreased flight intensity, and spent more time close to the speaker than when exposed to playback with a high switching rate. Previous studies have connected a stronger response during simulated intrusion with higher calling frequencies, reduced song production, increased flight activity, and a longer stay in the vicinity of the speaker (Pickstock and Krebs 1980; Slater 1981; Slater and Catchpole 1990; Leitão and Riebel 2003; Brumm and Ritschard 2011). This would indicate that playback with the long-bout treatment and a lower song-type switching rate induced a stronger response in the chaffinch during simulated territorial intrusion. The only discrepancy observed here lies in the decreased flight intensity in response to a lower switching rate. A similar reaction to lower switching rate was observed in western meadowlarks, which, like the chaffinches studied here, decreased their flight intensity (Horn and Falls 1988). Differences in flight intensity may result from habitat characteristics, for example differences in the density of vegetation and in the availability of suitable landing spots. Males may also increase flight activity to visually locate an intruder while avoiding a closer approach (Osiejuk et al. 2007a), which could be interpreted as cautious response to a more intimidating song (Searcy et al. 2000). It is reasonable to suppose that males may avoid approaching an 

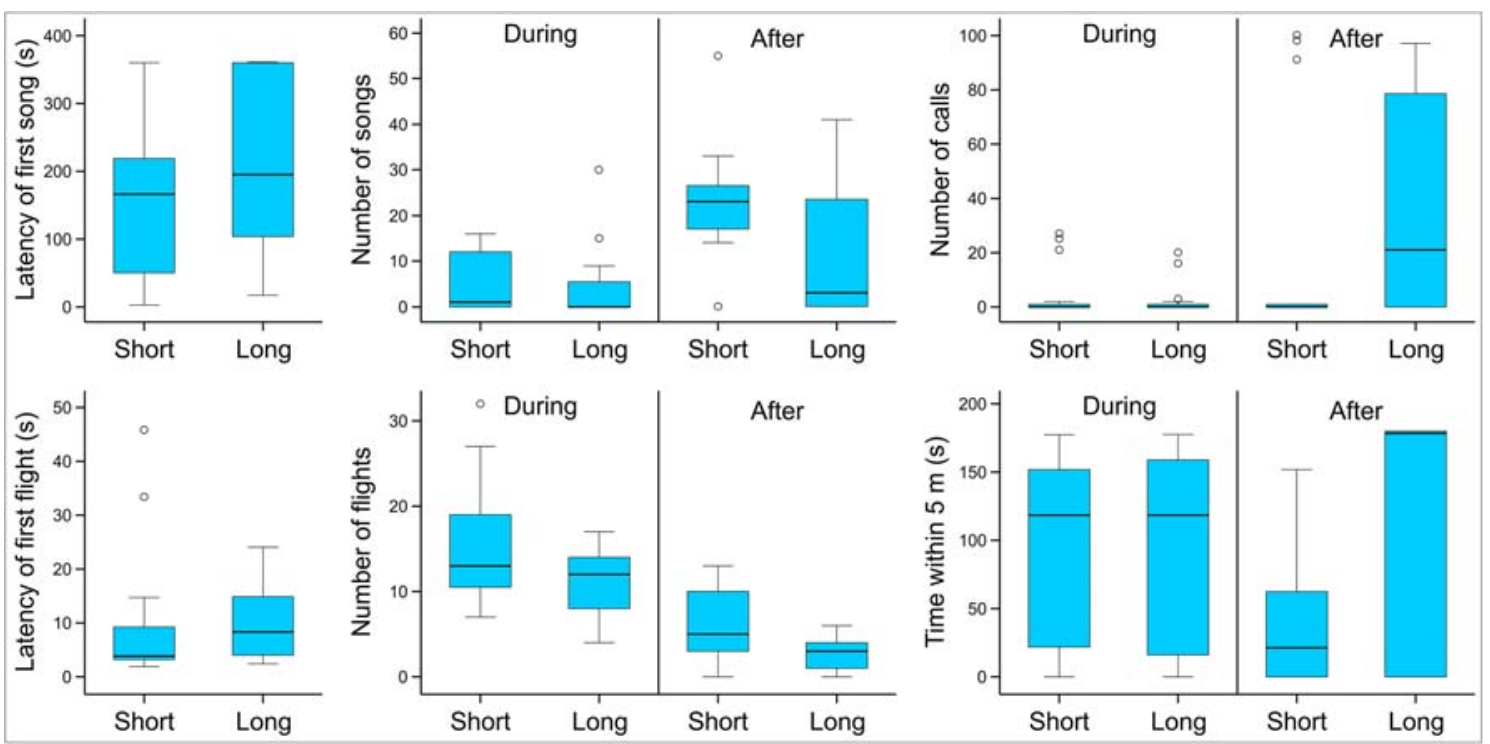

Fig. 2 Box and whisker plots showing the latency of first song after playback start, latency of first flight after playback start, and eight other response variables measured from male chaffinches tested with playback of short- and long-bout treatments. Significant differences between

treatments were found only for the number of flights after playback (Mann-Whitney $U$ test, $p=0.042$ ). Boxes indicate median and first and third quartiles. Whiskers represent the minimal and maximal values within 1.5 times the interquartile range. Open circles are outliers

intruder if they assess their own abilities to defend the territory as inferior to those of the rival. Despite this discrepancy, our findings regarding the vocal response, together with the time spent near the speaker, provide strong evidence that switching rate is an agonistic signal in the chaffinch and that territorial males exhibit a stronger response toward rivals singing with a lower switching rate. Since switching rate is a continuous variable, it would be interesting to see how chaffinches react to lower (or higher) levels than those used in the current study. This could tell us more about the signal value carried by song switching and show whether males exhibit a peaked curve in their responses to threats of varying intensity (de Kort et al. 2009).

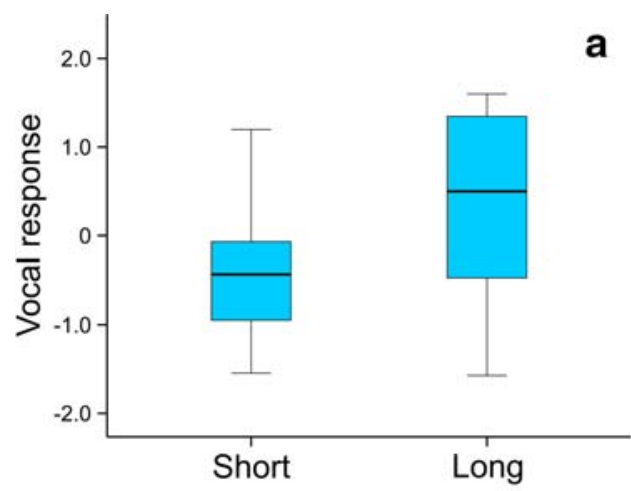

Fig. 3 Box and whisker plots showing significant differences (MannWhitney $U$ tests, $p<0.05$ ) in the responses of territorial males to playback with short- and long-bout durations, as described by PC1 (vocal response (a)) and PC2 (flight response (b)). Higher PC1 values indicate that in response to playback, the tested males produced more rain calls,
With respect to the criteria for aggressive signals proposed by Searcy and Beecher (2009), our results support the claims of previous studies that this behavior meets the "context criterion" (Riebel and Slater 1999a, 2000) and provide new evidence in support of the response criterion. Our study adds a new example of agonistic signaling in which switching frequency actually decreases in an aggressive context. This has been previously reported from the senders' perspective only in red-winged blackbirds (Searcy and Yasukawa 1990) and dunnocks (Langmore 1997), as well as from both senders' and receivers' perspectives in the banded wren (Molles and Vehrencamp 1999; Molles 2006). The final step in determining whether song switching is an aggressive signal in the

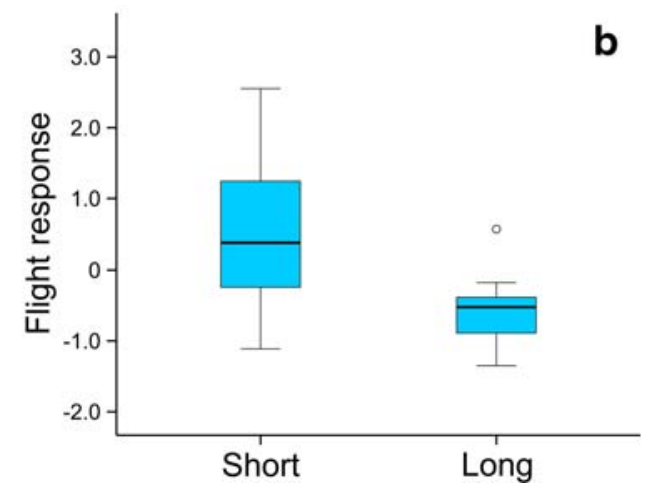

delivered fewer songs, and began to sing later. PC2 is positively correlated with the number of flights. Boxes indicate median and first and third quartiles. Whiskers represent the minimal and maximal values within 1.5 times the interquartile range. Open circles are outliers 
Table 2 Results of the five best-fitting GLMs explaining variation in the vocal response (PC1) of territorial chaffinch males between treatments with short- and long-bout durations

\begin{tabular}{llllrll}
\hline$\Delta$ AIC $_{\mathrm{C}}$ & $w_{i}$ & ER & Predictors & \multicolumn{1}{l}{$\beta$} & \multicolumn{1}{l}{ SE } & $p$ \\
\hline 0.00 & \multirow{2}{*}{0.40} & & Intercept & 1.614 & 0.6086 & 0.008 \\
& & & SONG RATE & -0.063 & 0.0291 & 0.030 \\
& & & TREATMENT & -0.689 & 0.3095 & 0.026 \\
1.16 & \multirow{2}{*}{0.18} & \multirow{2}{*}{2.22} & Intercept & 1.941 & 0.6858 & 0.005 \\
& & & DAY & -0.045 & 0.0461 & 0.328 \\
& & & SONG RATE & -0.065 & 0.0287 & 0.023 \\
& & & TREATMENT & -0.666 & 0.3056 & 0.029 \\
1.95 & \multirow{2}{*}{0.15} & 2.65 & Intercept & 1.237 & 0.7763 & 0.111 \\
& & & REPERTOIRE & 0.157 & 0.2028 & 0.440 \\
& & & SONG RATE & -0.063 & 0.0288 & 0.029 \\
& & & TREATMENT & -0.679 & 0.3068 & 0.027 \\
1.99 & \multirow{2}{*}{0.15} & \multirow{2}{*}{2.71} & Intercept & 0.380 & 0.2341 & 0.104 \\
& & & TREATMENT & -0.761 & 0.3311 & 0.022 \\
2.20 & \multirow{2}{*}{0.13} & \multirow{2}{*}{3.00} & Intercept & 1.408 & 0.6493 & 0.030 \\
& & & SONG RATE & -0.070 & 0.0312 & 0.025 \\
& & & & &
\end{tabular}

Predictors: day of season, DAY; repertoire of the tested male, REPERTOIRE; songs sung per minute during PRE phase, SONG RATE; playback treatment, TREATMENT. Significant values are in italic

chaffinch will involve investigating whether a lower switching rate predicts aggressive escalation by the signaler, thus fulfilling the predictive criterion (Searcy and Beecher 2009).

During this study, we also assessed the relationship between the characteristics of tested males' songs and the strength of their response to the playback. We observed that the spontaneous song rate, but not repertoire size, was a good predictor of the response to playback. Males singing with a higher spontaneous song rate tended to produce more songs after the start of playback, suppress rain call production, and decrease flight intensity. A similar correlation between song output before and after the beginning of playback has also been observed in other species, such as the corn bunting (Emberiza calandra; Osiejuk et al. 2007b. A study on variation in song rate during the breeding cycle reported that chaffinches sing with the highest rate before mating (Hanski and
Table 3 Results of the five best-fitting GLMs explaining variation in the flight response (PC2) of territorial chaffinch males between treatments with short- and long-bout durations

\begin{tabular}{|c|c|c|c|c|c|c|}
\hline$\Delta \mathrm{AIC}_{\mathrm{C}}$ & $w_{i}$ & ER & Predictors & $\beta$ & SE & $p$ \\
\hline \multirow[t]{4}{*}{0.00} & 0.38 & & Intercept & -0.176 & 0.6491 & 0.787 \\
\hline & & & REPERTOIRE & 0.315 & 0.1696 & 0.063 \\
\hline & & & SONG RATE & -0.059 & 0.0241 & 0.014 \\
\hline & & & TREATMENT & 10.229 & 0.2565 & $<0.001$ \\
\hline \multirow[t]{3}{*}{0.73} & 0.26 & 1.44 & Intercept & 0.585 & 0.5322 & 0.272 \\
\hline & & & SONG RATE & -0.059 & 0.0254 & 0.020 \\
\hline & & & TREATMENT & 10.208 & 0.2707 & $<0.001$ \\
\hline \multirow[t]{5}{*}{2.11} & 0.13 & 2.87 & Intercept & -0.030 & 0.6691 & 0.964 \\
\hline & & & MALES & -0.158 & 0.2018 & 0.435 \\
\hline & & & REPERTOIRE & 0.294 & 0.1700 & 0.083 \\
\hline & & & SONG RATE & -0.056 & 0.0241 & 0.019 \\
\hline & & & TREATMENT & 10.288 & 0.2648 & $<0.001$ \\
\hline \multirow[t]{4}{*}{2.25} & 0.12 & 3.09 & Intercept & 0.714 & 0.5382 & 0.185 \\
\hline & & & MALES & -0.213 & 0.2089 & 0.308 \\
\hline & & & SONG RATE & -0.056 & 0.0253 & 0.028 \\
\hline & & & TREATMENT & 10.289 & 0.2777 & $<0.001$ \\
\hline \multirow[t]{5}{*}{2.70} & 0.10 & 3.86 & Intercept & -0.215 & 0.7647 & 0.779 \\
\hline & & & DAY & 0.004 & 0.0402 & 0.924 \\
\hline & & & REPERTOIRE & 0.320 & 0.1760 & 0.069 \\
\hline & & & SONG RATE & -0.059 & 0.0242 & 0.015 \\
\hline & & & TREATMENT & 10.227 & 0.2571 & $<0.001$ \\
\hline
\end{tabular}

Predictors: day in season, DAY; other singing males in background, MALES; repertoire of the tested male, REPERTOIRE; songs per minute sang during PRE phase, SONG RATE; playback treatment, TREATMENT. Significant values are in italic

Laurila 1993). This suggests that the spontaneous song rate of chaffinch males indicates their motivation and willingness to defend their resources.

Song rate seems to be a reliable signal of competitive abilities, since it has a direct energy cost (reviewed in Vehrencamp 2000; Searcy et al. 2014). Individuals may easily compare their respective song rates in order to avoid the consequences associated with physical fights (Bradbury and Vehrencamp 2011). Together, this suggests that a male's response may be
Fig. 4 Relationship between the number of songs sung per minute by tested males during the PRE phase and their vocal (PC1 (a)) and flight $(\mathrm{PC} 2(\mathbf{b}))$ response to playback. Circles: males treated with short-bout treatment; triangles: males treated with long-bout treatment
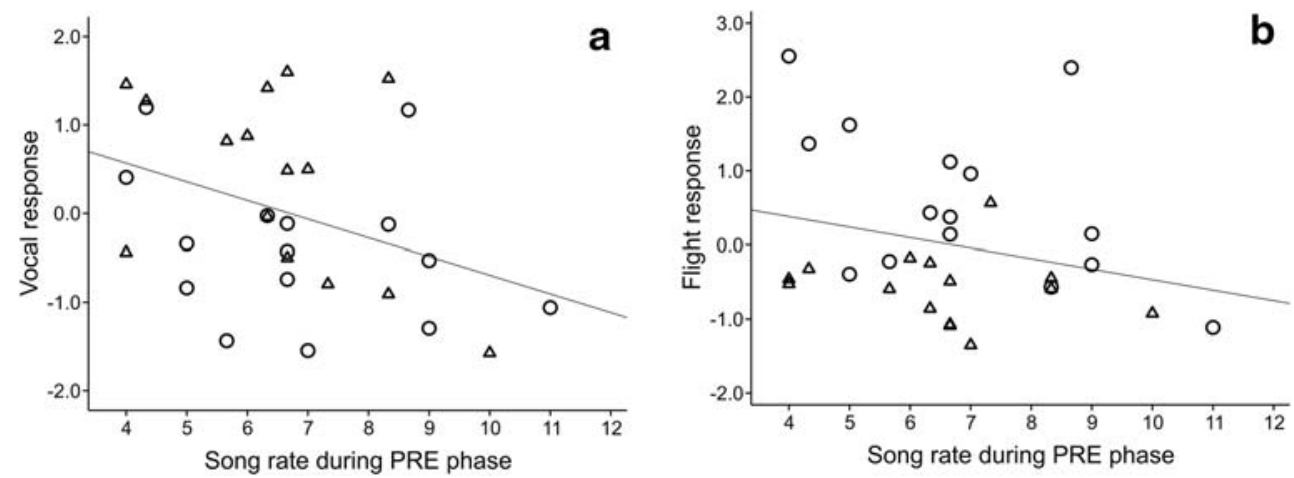
predicted from his song production rate, which has been found to be associated with motivation, arousal, and the level of aggression in various songbirds, including the song sparrow (Kramer et al. 1985), great tit (Weary et al. 1988), and wood warbler (Phylloscopus sibilatrix; Szymkowiak and Kuczyński 2017). Indeed, previous studies found that in the black-capped chickadee, a high song rate reliably predicted an attack (Baker et al. 2012), while in the chiffchaff (Phylloscopus collybita), males that sang faster also physically attacked the loudspeaker during the experiment (Linhart et al. 2013). To clarify this point in the chaffinch, a study testing the role of song rate in male-male interactions from both the senders' and receivers' perspectives would be valuable.

Interestingly, male chaffinches intensified the production of rain calls both in response to low switching rate as well as when singing with a lower spontaneous song rate. Rain calls have been suggested to be evoked by moderate danger (Marler 1956) and function as a substitute for song (Detert and Bergmann 1984; Saur et al. 1996). A recent study showed that rain calls were most numerous after the playback phase of the experiment (Budka et al. 2019). Like Budka et al. (2019), we had the subjective impression that males sometimes changed the amplitude of their rain calls, although we did not measure vocal amplitudes. Low-amplitude songs and calls are often used by songbirds in an aggressive context during territorial interactions (e.g., Hof and Hazlett 2010; Searcy et al. 2014; Akçay et al. 2015; Jakubowska and Osiejuk 2018). If rain calls are a substitute for song and are also used to maintain territory occupancy, their low-amplitude versions may be used in a similar way as soft songs, in order to confirm if the intruder is still present.

In conclusion, our study provides novel experimental evidence on the role of song-switching rate from the receiver's perspective in the chaffinch. We provide a new and important example of a lower switching rate serving as an agonistic signal: territorial chaffinch males exhibited a stronger response toward rivals singing with a lower switching rate, which to date has been demonstrated in only a few species. Future tests of whether a low song-type switching rate is predictive of an attack (thus fulfilling the "predictive criterion"; Searcy and Beecher 2009) would provide an answer as to whether song switching is an aggressive signal in the chaffinch. We furthermore observed that the response to playback could be predicted from the undisturbed song rate of tested males; further studies should therefore focus on the role of song rate in territorial disputes in the chaffinch. Finally, given our findings regarding rain calls, it remains an open question exactly what type of role they play in territory maintenance and male-male interactions.

Acknowledgments We would like to thank Pavel Linhart, Paweł Ręk, Henrik Brumm, and two anonymous reviewers for the helpful comments on the manuscript. Lindsay Higgins corrected the English.
Funding information This work was supported by the Polish National Science Center (grant number 2013/09/N/NZ8/03204).

Data availability The datasets generated and/or analyzed during the current study are available from the corresponding author on reasonable request.

\section{Compliance with ethical standards}

Conflict of interest The authors declare that they have no conflict of interest.

Ethical approval All applicable international, national, and/or institutional guidelines for the care and use of animals were followed. Our study did not require approval by a local ethical commission. According to the Act on Experiments on Animals (Disposition No. 289 from 2005), playback experiments do not fall within the authority of the Local Ethical Commission in Poland and its approval was not required. Tomasz Osiejuk has a certificate (No. 1952/2015) given by the Polish Laboratory Animal Science Association, which is necessary for any experiments with animals. Playback trials were kept brief to minimize disturbance to our subjects.

Open Access This article is licensed under a Creative Commons Attribution 4.0 International License, which permits use, sharing, adaptation, distribution and reproduction in any medium or format, as long as you give appropriate credit to the original author(s) and the source, provide a link to the Creative Commons licence, and indicate if changes were made. The images or other third party material in this article are included in the article's Creative Commons licence, unless indicated otherwise in a credit line to the material. If material is not included in the article's Creative Commons licence and your intended use is not permitted by statutory regulation or exceeds the permitted use, you will need to obtain permission directly from the copyright holder. To view a copy of this licence, visit http://creativecommons.org/licenses/by/4.0/.

\section{References}

Akçay Ç, Anderson RC, Nowicki S, Beecher MD (2015) Quiet threats: soft song as an aggressive signal in birds. Anim Behav 105:262-274

Alatalo RV, Glynn C, Lundberg A (1990) Singing rate and female attraction in the pied flycatcher: an experiment. Anita Behav 39:601-603

Baker TM, Wilson DR, Mennill DJ (2012) Vocal signals predict attack during aggressive interactions in black-capped chickadees. Anim Behav 84:965-974

Ballentine B, Searcy WA, Nowicki S (2008) Reliable aggressive signalling in swamp sparrows. Anim Behav 75:693-703

Balsby TJS, Eldermire ERB, Schnell JK, Poesel A, Walsh RE, Bradbury JW (2017) Function of vocalization length and warble repertoire size in orange-fronted conures. Anim Behav 134:301-310

Botero CA, Vehrencamp SL (2007) Responses of male tropical mockingbirds (Mimus gilvus) to variations in within-song and between-song versatility. Auk 124:185-196

Bradbury JW, Vehrencamp SL (2011) Principles of animal communication. Sinauer Associates, Sunderland

Brumm H, Ritschard M (2011) Song amplitude affects territorial aggression of male receivers in chaffinches. Behav Ecol 22:310-316

Brumm H, Slater PJB (2006) Ambient noise, motor fatigue, and serial redundancy in chaffinch song. Behav Ecol Sociobiol 60:475-481

Brumm H, Lachlan RF, Riebel K, Slater PJB (2009) On the function of song type repertoires: testing the "antiexhaustion hypothesis" in chaffinches. Anim Behav 77:37-42 
Budka M, Matyjasiak P, Typiak J, Okołowski M, Zagalska-Neubauer M (2019) Experienced males modify their behaviour during playback: the case of the chaffinch. J Ornithol 160:763-684

Byers BE (2017) Chestnut-sided warblers use rare song types in extreme aggressive contexts. Anim Behav 125:33-39

Catchpole CK, Slater PJB (2008) Bird song: biological themes and variations. Cambridge University Press, New York

de Kort SR, Eldermire ERB, Cramer ERA, Vehrencamp SL (2009) The deterrent effect of bird song in territory defense. Behav Ecol 20:200-206

Deoniziak K, Osiejuk TS (2016) Disentangling relations among repertoire size, song rate, signal redundancy and ambient noise level in European songbird. Ethology 122:734-744

Detert H, Bergmann HH (1984) Regenrufdialekte von Buchfinken (Fringilla coelebs L.): Untersuchungen an einer Population von Mischrufern. Oekol Vögel 6:101-118

Dobson CW, Lemon RE (1975) Re-examination of the monotonythreshold hypothesis in bird song. Nature 257:126-128

Grunst ML, Grunst AS (2014) Song complexity, song rate, and variation in the adrenocortical stress response in song sparrows (Melospiza melodia). Gen Comp Endocr 200:67-76

Haftorn S (1995) Coal tit Parus ater song repertoires and the Beau Geste hypothesis. J Ornithol 136:279-283

Hanski IK, Laurila A (1993) Variation in song rate during the breeding cycle of the chaffinch, Fringilla coelebs. Ethology 93:161-169

Hartshorne C (1956) The monotony-threshold in singing birds. Auk 83: 176-192

Hesler N, Mundry R, Sacher T, Coppack T, Bairlein F, Dabelsteen T (2012) Song repertoire size correlates with measures of body size in Eurasian blackbirds. Behaviour 149:645-665

Hof D, Hazlett N (2010) Low-amplitude song predicts attack in a North American wood warbler. Anim Behav 80:821-828

Hofstad E, Espmark Y, Moksnes A, Haugan T, Ingebrigtsen M (2002) The relationship between song performance and male quality in snow buntings (Plectrophenax nivalis). Can J Zool 80:524-531

Horn AG, Falls JB (1988) Responses of western meadowlarks, Sturnella neglecta, to song repetition and contrast. Anim Behav 36:291-293

Horn AG, Falls JB (1991) Song switching in mate attraction and territory defense by western meadowlarks (Sturnella neglecta). Ethology 87: 262-268

Horn AG, Leonard ML, Ratcliffe L, Shackleton SA, Weisman RG (1992) Frequency variation in songs of black-capped chickadees (Parus atricapillus). Auk 109:847-852

Hughes AL (2008) Temporal pattern of vocalization type usage in singing sessions of male tyrant flycatchers (Tyranninae). J Avian Biol 39: 24-29

Jakubowska A, Osiejuk TS (2018) Soft songs in male ortolan buntings are used in an aggressive context but are not an aggressive signal. Ethology 124:549-558

Kaiser HF, Rice J (1974) Little jiffy, Mark IV. Educ Phychol Meas 34: $111-117$

King SL, McGregor PK (2016) Vocal matching: the what, the why and the how. Biol Lett 12:20160666

Kramer HG, Lemon RE (1983) Dynamics of territorial singing between neighbouring song sparrows (Melospiza melodia). Behaviour 85: 198-223

Kramer HG, Lemon RE, Morris MJ (1985) Song switching and agonistic stimulation in the song sparrow (Melospiza melodia): five tests. Anim Behav 33:135-149

Krebs JR (1977) The significance of song repertoires: the Beau Geste hypothesis. Anim Behav 25:475-478

Krebs JR (1976) Habituation and song repertoires in the great tit. Behav Ecol Sociobiol 1:215-227

Krebs JR, Ashcroft R, Orsdol K (1981) Song matching in great tits Parus major L. Anim Behav 29:918-923
Lambrechts M, Dhondt AA (1988) The anti-exhaustion hypothesis: a new hypothesis to explain song performance and song switching in the great tit. Anim Behav 36:327-334

Langmore NE (1997) Song switching in monandrous and polyandrous dunnocks, Prunella modularis. Anim Behav 53:757-766

Larose DT, Larose CD (2015) Data mining and predictive analytics. John Wiley \& Sons, New Jersey

Leitão A, Riebel K (2003) Are good ornaments bad armaments? Male chaffinch perception of songs with varying flourish length. Anim Behav 66:161-167

Lemon RE (1968) The relation between organization and function of song in cardinals. Behaviour 32:158-177

Linhart P, Jaška P, Petrusková T, Petrusek A, Fuchs R (2013) Being angry, singing fast? Signaling of aggressive motivation by syllable rate in a songbird with slow song. Behav Process 100:139-145

Marler P (1956) The voice of the chaffinch and its function as a language. Ibis 98:231-261

Marshall-Ball L, Slater PJB (2004) Duet singing and repertoire use in threat signalling of individuals and pairs. Proc R Soc Lond B 271: S440-S443

Molles LE (2006) Singing complexity of the banded wren (Thryothorus pleurostictus): do switching rate and song-type diversity send different messages? Auk 123:991-1003

Molles LE, Vehrencamp SL (1999) Repertoire size, repertoire overlap, and singing modes in the Banded Wren (Thryothorus pleurostictus). Auk 116:667-689

Morton ES, Young K (1986) A previously undescribed method of song matching in a species with a single song 'type', the Kentucky warbler (Oporornis formosus). Ethology 73:334-342

Moseley DL, Lahti DC, Podos J (2013) Responses to song playback vary with the vocal performance of both signal senders and receivers. Proc R Soc B 280:20131401

Nielsen BMB, Vehrencamp SL (1995) Responses of song sparrows to song-type matching via interactive playback. Behav Ecol Sociobiol 37:109-117

Opaev A, Kolesnikova Y, Liu M, Kang Z (2019) Singing of Claudia's leaf-warbler (Phylloscopus claudiae) in aggressive contexts: role of song rate, song type diversity and song type transitional pattern. J Ornithol 160:297-304

Osiejuk TS, Łosak K, Dale S (2007a) Cautious response of inexperienced birds to conventional signal of stronger threat. J Avian Biol 38:644-649

Osiejuk TS, Ratyńska K, Cygan JP (2007b) Corn bunting (Miliaria calandra) males respond differently to alternating and overlapping playback of song. J Ethol 25:159-168

Phillips JN, Derryberry EP (2017) Vocal performance is a salient signal for male-male competition in white-crowned sparrows. Auk 134: $564-574$

Pickstock JC, Krebs JR (1980) Neighbour-stranger song discrimination in the chaffinch. J Ornithol 121:105-108

Radesäter T, Jakobsson S, Andbjer N, Bylin A, Nyström K (1987) Song rate and pair formation in the willow warbler Phylloscopus trochilus. Anim Behav 35:1645-1651

Richards SA (2005) Testing ecological theory using the informationtheoretic approach: examples and cautionary results. Ecology 86: 2805-2814

Riebel K, Slater PJB (1998) Testing female chaffinch song preferences by operant conditioning. Anim Behav 56:1443-1453

Riebel K, Slater PJB (1999a) Song type switching in the chaffinch: timing or counting? Anim Behav 57:655-661

Riebel K, Slater PJB (1999b) Do male chaffinches Fringilla coelebs copy song sequencing and bout length from their tutors? Ibis 141:680-683

Riebel K, Slater PJB (2000) Testing the flexibility of song type bout duration in the chaffinch, Fringilla coelebs. Anim Behav 59:1135-1142

Saur B, Maciejok J, Bergmann H-H (1996) Where to sing and where to call. Vocalizations of chaffinches Fringilla coelebs inside and outside their territories. Bioacoustics 6:273-279 
Searcy WA, Beecher MD (2009) Song as an aggressive signal in birds. Anim Behav 78:1281-1292

Searcy WA, Yasukawa K (1990) Use of the song repertoire in intersexual and intrasexual contexts by male red-winged blackbirds. Behav Ecol Sociobiol 27:123-128

Searcy WA, Nowicki S, Hogan C (2000) Song type variants and aggressive context. Behav Ecol Sociobiol 48:358-363

Searcy WA, Anderson RC, Nowicki S (2006) Bird song as a signal of aggressive intent. Behav Ecol Sociobiol 60:234-241

Searcy WA, Akçay C, Nowicki S, Beecher MD (2014) Aggressive signaling in song sparrows and other songbirds. Adv Stud Behav 46: $89-125$

Simpson BS (1985) Effects of location in territory and distance from neighbours on the use of song repertoires in Carolina wrens. Anim Behav 33:793-804

Slater PJB (1978) Beau Geste has problems. Anim Behav 26:304

Slater PJB (1981) Chaffinch song repertoires: observations, experiments and discussion of their significance. Z Tierpsychol 56:1-24

Slater PJB (1983) Sequences of song in chaffinches. Anim Behav 31: 272-281

Slater PJB, Catchpole CK (1990) Responses of the two chaffinch species on Tenerife (Fringilla teydea and Fringilla coelebs tintillon) to playback of the song of their own and the other species. Behaviour 115: 143-152

Slater PJB, Ince SA (1979) Cultural evolution in chaffinch song. Behaviour 71:146-166

Slater PJB, Ince SA, Colgan PW (1980) Chaffinch song types: their frequencies in the population and distribution between the repertoires of different individuals. Behaviour 75:207-218

Swaddle JP, Francis CD, Barber JR, Cooper CB, Kyba CC, Dominoni DM, Shannon G, Aschehoug E, Goodwin SE, Kawahara AY, Luther D, Spoelstra K, Voss M, Longcore T (2015) A framework to assess evolutionary responses to anthropogenic light and sound. Trends Ecol Evol 30:550-560

Symonds MRE, Moussalli A (2011) A brief guide to model selection multimodel inference and model averaging in behavioural ecology using Akaike's information criterion. Behav Ecol Sociobiol 65:13-21

Szymkowiak J, Kuczyński L (2017) Song rate as a signal of male aggressiveness during territorial contests in the wood warbler. J Avian Biol 48:275-283

ten Cate C, Slabbekoorn H, Ballintijn MR (2002) Birdsong and male-male competition: causes and consequences of vocal variability in the collared dove (Streptopelia decaocto). Adv Stud Behav 31:31-75

Todt D, Naguib M (2000) Vocal interactions in birds: the use of song as a model in communication. Adv Stud Behav 29:247-296

Vehrencamp SL (2000) Handicap, index, and conventional signal elements of bird song. In: Espmark Y, Amundsen T, Rosenqvist G (eds) Animal signals: signalling and signal design in animal communication, 1st edn. Tapir Academic Press, Trondheim, pp 277-300

Weary DM, Lemon RE (1988) Evidence against the continuityversatility relationship in birdsong. Anim Behav 36:1379-1383

Weary DM, Krebs JR, Eddyshaw R, McGregor PK, Horn A (1988) Decline in song output by great tits - exhaustion or motivation. Anim Behav 36:1242-1244

Weary DM, Lambrechts MM, Krebs JR (1991) Does singing exhaust male great tits? Anim Behav 41:540-542

Yasukawa K, Searcy WA (1985) Song repertoires and density assessment in red-winged blackbirds: further tests of the Beau Geste hypothesis. Behav Ecol Sociobiol 16:171-176

Publisher's note Springer Nature remains neutral with regard to jurisdictional claims in published maps and institutional affiliations. 